\title{
Commentary Isoflavones and women's health
}

\section{Trevor Powles}

\author{
Parkside Hospital, Wimbledon, London \\ Corresponding author: Trevor Powles (e-mail: amccabe@parkside-hospital.co.uk) \\ Published: 6 April 2004 \\ Breast Cancer Res 2004, 6:140-142 (DOI 10.1186/bcr796) \\ (C) 2004 BioMed Central Ltd \\ See related Research article: http://breast-cancer-research.com/content/6/3/R170
}

\begin{abstract}
There is evidence that diets which contain high levels of phytoestrogenic isoflavanoids are associated with a low incidence of osteoporosis and menopausal vasomotor symptoms. Plant extracts such as red clover, which contain high levels of isoflavanoids, have been used to reduce menopausal symptoms and have been shown to reduce bone loss in healthy women. A placebo-controlled clinical trial [ISRCTN42940165] of red clover is reported in this issue of Breast Cancer Research and shows that these phytoestrogens do not cause any oestrogenic increase in breast density, which would indicate that they are unlikely to cause an increased risk of breast cancer.
\end{abstract}

Keywords: isoflavones, red clover, women's health

\section{Introduction}

Vasomotor symptoms such as hotflushes and night sweats, associated with insomnia and cognitive dysfunction, commonly occur in women after the menopause and are caused by a lowering of oestrogen levels in the hypothalamus due to ovarian failure. These symptoms are the main reason for women taking oestrogen (sometimes with a progestin) as hormone replacement therapy (HRT). An added advantage of taking oestrogen is that it also prevents bone loss and osteoporotic fractures. However, HRT has been associated with an increase in breast cancer, uterine cancer, thromboembolism, heart disease and stroke [1].

Because of these problems, there is now a substantial effort to develop drugs with a spectrum of oestrogenic and anti-oestrogenic activity (the Selective Estrogenic Receptor Modulators or SERMS), which give a better profile of activity than oestrogen for women's health benefits. For example, the SERM raloxifene (Evista, Eli Lilly) has been shown to reduce the risk of breast cancer [2], osteoporotic fractures in the spine [3], and heart disease in women at high risk [4], but it is not effective at reducing vasomotor and cognitive symptoms and, like oestrogen, still causes an increase in thromboembolism. The search therefore continues to find the ideal SERM that has a spectrum of oestrogenic and antioestrogenic activity which would reduce vasomotor symptoms, improve cognitive dysfunction, reduce breast cancer, uterine cancer and perhaps ovarian cancer, reduce the risk of osteoporotic fracture, heart disease and stroke, and not cause an increase in thromboembolism. This is theoretically possible.

\section{Natural products and women's health}

For many years plant extracts have been used for controlling the vasomotor symptoms of the menopause, which would indicate that there are naturally occurring phytoestrogenic agents in these plants [5]. A group of candidate agents likely to be oestrogenically active in these plant extracts are the isoflavones. The question is then raised as to whether these extracts, used to control vasomotor symptoms, have adverse effects like HRT, and if they increase breast cancer risk. There is good epidemiological evidence, however, that in Asian populations where the diet is high in isoflavones, from sources such as soya [6] there is a low incidence of breast cancer, osteoporosis, heart disease and stroke with 
no evidence of an increase in thromboembolism. It is therefore possible that some of these agents may have an ideal SERM spectrum of activity. This justifies rigorous testing in clinical trials in order to establish that these natural products, which are easily available and widely used to alleviate hot flushes, are not oestrogenic on the breast and not likely to increase breast cancer risk.

One of the main problems with assessing natural products for health benefits is the lack of good clinical trial data. Most of the evidence is, at best, anecdotal involving the uncontrolled use of products of unknown quality. There is no doubt that many of these traditional 'medicines' are biologically active and by a process of natural selection may be beneficial. However, like pharmaceutical products, the beneficial effects are likely to be dose dependent and it is likely that these active agents would have a spectrum of biological activity that may cause toxicity. Without good clinical trial data and with no quality control of the product it is unlikely these agents would consistently provide therapeutic benefit.

It therefore makes sense that if there are good reasons to suppose that a natural product may have a therapeutic benefit in humans (i.e. there is a reasonable hypothesis to be tested) it should be tested according to the strict scientific methodology of clinical research. This means that the product, usually an extract of a plant, should be of known quality and quantity so the exact amounts of the known constituents are reproducibly present in the medication. (This usually means quality assurance by gas liquid chromatography and mass spectrometry of all preparations). The product then needs to be tested by the established methodology of clinical research in order to provide reliable results. This will usually require double blind placebo controlled clinical trials with clearly defined outcomes and adequate statistical power. Potential toxicity needs to be carefully evaluated. Only then is it possible to evaluate the overall value of use of the product as a medication for humans.

\section{Red clover isoflavone trials}

On this basis, the paper in this issue of the journal, by Atkinson and colleagues, [7] reports a randomised, doubleblind, placebo-controlled trial of Promensil (Novogen), an extract of red clover, given to 205 pre- and postmenopausal healthy women with radiologically dense breasts (an established oestrogenic risk factor for breast cancer). Promensil is an extract of red clover containing very accurately determined amounts of the principal isoflavanoids: biochanin $A$, formononetin, genistein and daidzein (total isoflavanoid content of $40 \mathrm{mg}$ per tablet) [8]. The trial is well designed with the principal objective of evaluating any adverse oestrogenic effect of red clover, at a dose of $40 \mathrm{mg}$ of isoflavones per day, on breast density as a surrogate marker of increased breast cancer risk.
The study has shown that, at this dose of Promensil, there is no evidence of any increase in radiological breast density in women who already have increased breast density, in spite of the well-documented evidence that HRT will increase breast density and tamoxifen will reduce breast density. There is little other data relating to isoflavones and breast density, with only one small trial involving 30 premenopausal women receiving $100 \mathrm{mg}$ of isoflavones versus placebo for one year showing no significant effect on breast density [9]. Larger trials are needed to evaluate the effect of these higher doses of isoflavones on healthy women particularly those with an increased breast density.

Rather surprisingly, the trial reported by Atkinson and colleagues failed to show any beneficial effect on menopausal symptoms or reduction in follicle-stimulating hormone in post menopausal women, indicating a lack of oestrogenic activity of $40 \mathrm{mg}$ per day of Promensil on the hypothalamus. A recent small but well designed trial reported by van de Weijer showed that 12 weeks of $80 \mathrm{mg}$ per day of Promensil in 30 healthy women with marked vasomotor symptoms caused a $44 \%$ reduction in hot flushes for women on Promensil compared to placebo $(P<0.01)$ [10]. The negative result in the trial reported by Atkinson and colleagues may be because women in the trial women were not recruited because of moderate or marked hot flushes and the dose of Promensil was only $40 \mathrm{mg}$ per day.

In this same trial, a recent paper reports the results of bone density and bone marker measurements in the 205 women [11]. The results shows that Promensil will significantly reduce the loss of bone mineral density in the lumber spine compared to placebo $(P<0.05)$, with an associated increase in markers of bone formation $(P<0.05)$ indicating a beneficial oestrogenic effect of $40 \mathrm{mg}$ per day of isoflavones for one year on the bones.

\section{Conclusion}

Overall, this trial has shown encouraging evidence of a significant oestrogenic effect of $40 \mathrm{mg}$ of isoflavanoids on bone with no evidence of an adverse oestrogenic effect on breast density. The possible benefit on vasomotor symptoms has not been adequately tested in this trial. Larger trials, involving more women treated for a longer period and perhaps at higher doses, are needed to test for possible overall clinical benefit in healthy women. At this time it is reassuring that there is no evidences that the widespread use of isoflavones to treat hot flushes is likely to be harmful.

\section{Competing interests}

TP is principle investigator for a clinical trial of red clover in healthy women. 


\section{References}

1. Writing Group for the Women's Health Initiative Investigators: Risks and benefits of estrogen plus progestin in healthy postmenopausal women: principal results from the Women's Health Initiative Randomized Controlled Trial. JAMA 2002, 288:321-333.

2. Cummings SR, Norton L, Eckert S, Grady D, Cauley J, Knickerboker R, Black DM, Nickelsen T, Glusmanj, Krueger K: Raloxifene reduces the risk of breast cancer and may decrease the risk of endometrial cancer in post-menopausal women. Two-year findings from the multiple outcomes of raloxifene evaluation (MORE) trial. Proc Am Soc Clin Oncol. 1998, 17:2a.

3. Ettinger B, Black DM, Mitlak BH, Knickerbocker RK, Nickelsen T, Genant HK, Christiansen C, Delmas PD, Zanchetta JR, Stakkestad J, Glüer CC, Krueger K, Cohen FJ, Eckert S, Ensrud KE, Avioli LV, Lips P, Steven R. Cummings SR, and for the Multiple Outcomes of Raloxifene Evaluation Investigators: Reduction of vertebral fracture risk in postmenopausal women with osteoporosis treated with raloxifene: results from a 3-year randomized clinical trial. JAMA 1999, 282:637-645.

4. Barrett-Connor E, Grady D, Sashegyi A, Anderson PW, Cox DA, Hoszowski K, Rautaharju P, Harper KD; MORE Investigators (Multiple Outcomes of Raloxifene Evaluation): Raloxifene and cardiovascular events in osteoporotic postmenopausal women: four-year results from the MORE (Multiple outcomes of raloxifene evaluation) randomized trial. JAMA 2002, 287:847-857.

5. Adlercreutz $\mathrm{H}$, Mazur W: Phyto-oestrogens and Western diseases. Ann Med 1997, 29:95-120

6. van de Kleijn MJ, van der Schouw YT, Wilson PW, Adlercreutz H, Mazur W, Grobbee DE, Jacques PF: Intake of dietary phytoestrogens is low in postmenopausal women in the United States: the Framingham study(1-4). J Nutr 2001, 131:18261832.

7. Atkinson C, Warren RML, Sala E, Dowsett M, Dunning AM, Healey CS, Runswick S, Day NE, Bingham SA: Red cloverderived isoflavones and mammographic breast density: a double-blind, randomized, placebo-controlled trial [ISRCTN42940165]. Breast Cancer Res 2004, 6:R170-R179

8. Setchell KD, Brown NM, Desai P, Zimmer-Nechemias L, Wolfe BE, Brashear WT, Kirschner AS, Cassidy A, Heubi JE: Bioavailability of pure isoflavones in healthy humans and analysis of commercial soy isoflavone supplements. J Nutr 2001, Suppl: 1362S-1375S.

9. Maskarinec G, Williams AE, Carlin L: Mammographic densities in a one-year isoflavone intervention. Eur J Cancer Prev 2003, 12:165-169.

10. Van de Weijer PHM, Barentsen R: Isoflavones from red clover (Promensil) significantly reduce menopausal hot flush symptoms compared with placebo. Maturitas 2002, 42:187-193.

11. Atkinson C, Compston JE, Day NE, Dowsett M, Bingham SA: The effects of phytoestrogen isoflavones on bone density in women: a double-blind, randomised, placebo-controlled trial. Am J Clin Nutr 2004, 79:326-333

\section{Correspondence}

Trevor Powles, Parkside Oncology Clinic, 49, Parkside, Wimbledon, London SW19 4BX. Tel: +44 (0)20 8247 3384; fax: +44 (0)20 8247

3385; e-mail: amccabe@parkside-hospital.co.uk 